\title{
Pulmonary hypertension in infants with chronic lung disease: non-invasive evaluation and short term effect of oxygen treatment
}

\author{
Avram Benatar, Jane Clarke, Michael Silverman
}

\begin{abstract}
A total of 45 examinations on 30 premature infants with chronic lung disease (CLD) of prematurity were made using Doppler echocardiography. Pulmonary systolic time intervals and tricuspid regurgitant velocity were measured to assess the prevalence of pulmonary hypertension and short term responsiveness of the pulmonary circulation to oxygen. Twelve preterm infants matched for gestational age, served as controls. Tricuspid regurgitation (TR) was detected in 14 of the patients. Eleven of those with TR had pulmonary hypertension, of whom eight responded to oxygen treatment. Of the remaining three patients with 'fixed' pulmonary hypertension, one subsequently died. The detection of TR was the basis of the preferred method for measuring pulmonary artery pressure (Ppa) non-invasively, but the degree of correlation between the Ppa estimated from $T R$ and pulmonary systolic time intervals was high $(r=-0.84, p=<0.001)$.

In the absence of $T R$, systolic time intervals are an effective way to monitor pulmonary artery pressure in infants with CLD. Without these measurements, it would have been impossible to predict which subjects had pulmonary hypertension, and which might respond to oxygen treatment.

(Arch Dis Child 1995; 72: F14-F19)
\end{abstract}

Keywords: pulmonary hypertension, chronic lung disease, oxygen treatment, non-invasive evaluation.

Chronic lung disease (CLD) of prematurity is still a major problem in babies who survive neonatal intensive care. Its incidence in those infants who require ventilation for respiratory distress syndrome and who survive varies from $10 \%$ to $20 \%$, according to gestational age ${ }^{1}$ and definition. Infants with CLD are at risk of developing pulmonary hypertension, which is a predictor of subsequent morbidity and mortality. ${ }^{2-5}$ Heart failure associated with severe pulmonary hypertension used to be a common cause of death. ${ }^{5}$

There is a good deal of evidence that pulmonary hypertension in CLD is extremely sensitive to oxygen ${ }^{6}$ and that this may be responsible for the increased survival of infants with CLD given appropriate, longterm oxygen treatment. As there are major differences between individual infants in terms of the relation between pulmonary artery pressure (Ppa) and arterial oxygen saturation $\left(\mathrm{SaO}_{2}\right),{ }^{67}$ the level of longterm oxygen treatment may need to be determined not simply by an arbitrary target of $\mathrm{SaO}_{2}$, but by the degree of hypoxic pulmonary vascular responsiveness of individual infants. This would have the advantage that oxygen insensitive babies might be able to withdraw from oxygen treatment sooner than otherwise, while sensitive babies could be monitored more assiduously. However, a programme based on the control of pulmonary hypertension needs a safe and practical means of cardiovascular monitoring.

Cardiac catheterisation has been the gold standard for the measurement of pulmonary artery pressure. ${ }^{2}$ This procedure carries significant risk in babies with CLD and is only available in paediatric cardiology units. Doppler echocardiography is proving to be a useful, non-invasive indirect way of assessing pulmonary artery pressure. Two principal methods are available. The first requires the presence of a tricuspid regurgitant jet from which the pressure gradient across the valve can be calculated from peak velocity. This allows the peak systolic right ventricular pressure and, with assumptions about the right atrial pressure, the absolute pulmonary artery systolic pressure to be calculated. ${ }^{8-12}$ The second method uses pulmonary systolic time intervals and ratios. Although this method, technically, is much easier to perform, it cannot provide an absolute value for Ppa. In this method the Doppler wave form sampled from the pulmonary artery is analysed for the acceleration time (the time to peak velocity, AT) and the total right ventricular ejection time (ET) is also measured. Studies in children and adults have shown a close inverse correlation between the dimensionless ratio AT:ET and Ppa measured directly at cardiac catheterisation. ${ }^{10-17}$ Both of these Doppler methods correlate with invasive measurements of Ppa. ${ }^{10-18}$

The aims of this study were to establish the prevalence of tricuspid regurgitation in infants with CLD; to estimate systolic right heart pressures from the tricuspid regurgitant jet velocity; to determine the correlation between calculated right heart pressures and Doppler pulmonary flow-velocity intervals; to compare values for pulmonary flow indices with preterm controls and with published reference data; and more importantly to assess the effects of oxygen on Doppler derived values of Ppa in infants with CLD and pulmonary hypertension.
Accepted 16 September 1994 
Methods

Group I comprised 30 patients (23 boys) with CLD who had been previously ventilated for hyaline membrane disease and were oxygen dependent beyond 35 weeks' gestation. Gestational age at birth ranged from 23 to 33 weeks and birth weight 600 to $1760 \mathrm{~g}$ (mean $1135 \mathrm{~g}$ ). All were under 30 months of age at the time of study and were in sinus rhythm. Congenital heart disease and a patent ductus arteriosus were excluded by clinical examination, electrocardiography, and echocardiography. Forty five Doppler examinations were carried out. Seven patients were studied more than once, on separate occasions. Infants with CLD were sedated with chloral hydrate 100 $\mathrm{mg} / \mathrm{kg}, 30$ minutes before study.

Group II, the control subjects, consisted of 12 preterm infants (five boys), born consecutively over a seven month period, who either had no neonatal respiratory problems, or very mild respiratory distress (less than three days' ventilation and supplemental oxygen for less than seven days). Gestational age at birth was 27-32 weeks and birth weight 940-1780 g (mean $1346 \mathrm{~g}$ ). They were examined between 3 and 17 weeks after birth, at a mean postmenstrual age of 40 weeks (range 35 to 49 weeks). Control patients were examined during natural sleep.

\section{MONITORING}

Oxygen was given via nasal cannula to those patients still oxygen dependent at the time of study (16 out of 45 examinations) to maintain $\mathrm{SaO}_{2}$ above $94 \%$ (normoxia). The infants with CLD were monitored for oxygen saturation and heart rate using a pulse oximeter (Ohmeda Biox 3740, Louisville, USA) applied to the thumb or hand. Systemic blood pressure was not measured.

The study of control subjects was approved by the Hammersmith Hospital Ethics Committee and parental consent was given in all cases.

\section{DOPPLER EXAMINATIONS}

Tricuspid regurgitation velocity

Systolic right ventricular pressure was estimated from the tricuspid regurgitant jet detected by echoDoppler, as described before. ${ }^{10-12}$ A Toshiba SH 160 echocardiographic machine with a $3.75 \mathrm{MHz}$ real time steerable Doppler transducer was used for continuous wave Doppler interrogation of tricuspid regurgitation. Doppler recordings were taken from the subcostal, apical, and parasternal positions. The search for the signal of tricuspid regurgitation was performed with the aid of colour flow mapping to achieve optimal recording. To derive a systolic transtricuspid gradient, the modified Bernouilli equation was used. ${ }^{19} 20$ In infancy the mean right atrial pressure is low $(2-5 \mathrm{~mm} \mathrm{Hg}$, $0 \cdot 267-0.667 \mathrm{kPa}$ ) and was assumed to be zero in this study. ${ }^{21}$ This method of right ventricular pressure estimation, validated previously only in older children and adults, has recently been shown to be a reproducible and accurate technique in infants with tricuspid regurgitation. ${ }^{22}$

\section{Pulmonary flow indices}

The same scanner equipped with a 5 or $3 \cdot 75$ $\mathrm{MHz}$ duplex transducer was utilised for the study of pulmonary flow velocities. The short axis and high parasternal views were used, with the Doppler sample volume positioned just distal to the valve in the centre of the pulmonary artery. The electrocardiogram was recorded simultaneously. Analysis of the pulmonary velocity contour provided the acceleration time and right ventricular ejection time, which were measured with the incorporated Doppler measurement calipers and software. The acceleration time was measured as the time interval between the systolic Doppler waveform leaving the zero flow baseline and reaching its peak velocity. The right ventricular ejection time (ET) is the interval between the systolic Doppler waveform leaving and returning to the zero flow baseline. ${ }^{23}$ Five consecutive optimal beats with clearly defined envelopes were measured and averaged. For each beat, the R-R interval on the electrocardiogram and heart rate were measured with the incorporated calipers and software. Correction for different heart rates was performed by dividing the acceleration time by right ventricular ejection time (AT:ET), and dividing the acceleration time and AT:ET by the square root of the cycle length (that is, R-R interval in seconds) giving a corrected AT (ATc) and a corrected AT:ET (AT:ETc). ${ }^{17}$

\section{OXYGEN CHALLENGE}

Oxygen was given to assess its effect on pulmonary vascular resistance, and pulmonary systolic pressure and hence assess potential 'reactivity'. Thirteen patients (20 examinations) with baseline saturations of less than $95 \%$ and evidence of pulmonary hypertension from tricuspid regurgitation were given oxygen by funnel over the mouth and nose. The oxygen flow was adjusted so that the saturation rose to at least $95 \%$. Reactivity to oxygen was defined as a drop of at least $5 \mathrm{~mm} \mathrm{Hg}(0.667$ $\mathrm{kPa}$ ) peak systolic Ppa. Pulmonary flow velocity intervals were also recorded.

\section{STATISTICAL ANALYSIS}

The numerical variables are expressed as mean (standard deviation). A two tailed, unpaired $t$ test was used for statistical comparison between patients and controls. The 95\% confidence intervals for differences were calculated. Pulmonary arterial systolic pressures calculated from the tricuspid regurgitant velocity were correlated with pulmonary flow indices (AT:ET, AT:ETc and ATc) before and after oxygen challenge separately, using linear regression, and $95 \%$ confidence intervals were calculated. A paired $t$ test combined with a Bonferroni correction was used to assess the 


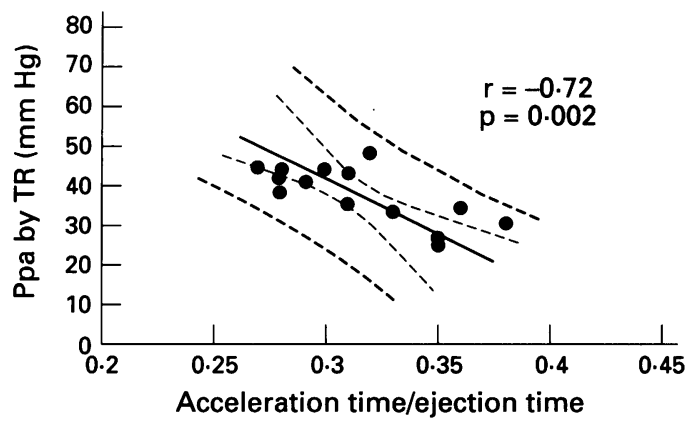

Figure $1 T R$ derived peak systolic pulmonary artery pressure (Ppa) plotted against AT:ET under basal conditions, with regression line (solid line). .......... confidence limits (95\%) for the regression line; -...-.-...: 95\% limits for estimating AT:ET for a given TR value.

significance of differences between variables before and after the administration of oxygen. The $95 \%$ confidence limits for estimating the AT:ET value corresponding to a given pulmonary systolic pressure by TR were also calculated before and after oxygen challenge.

\section{Results}

Forty five examinations were carried out in the 30 patients with CLD in group I. Good quality pulmonary pulsed Doppler proximal pulmonary artery flow velocity contours were obtained in all patients. No infant had pulmonary stenosis or right ventricular outflow obstruction. At the start of the study, when well sedated, measurable peak velocity signals of tricuspid regurgitation could be detected in 14 patients (20 of the 45 examinations, $\mathrm{pr}$ $44 \%$ ). Colour flow Doppler was helpful in steering the continuous wave beam. The detection of a transtricuspid regurgitant jet was unrelated to postnatal age, calculated systolic right ventricular pressures, or saturation. The detection of this jet was time consuming and required operator patience and use of several echocardiographic windows. In general, optimal flow velocity envelopes were obtained during the inspiratory phase of respiration. In each of six patients tricuspid regurgitation was detected on two separate examinations.

From TR calculation, two patients were found to have normal pulmonary systolic pressures $(<29 \mathrm{~mm} \mathrm{Hg}, 3.87 \mathrm{kPa})$, six had pressures between $30-39 \mathrm{~mm} \mathrm{Hg} \mathrm{(4 \cdot 00-5 \cdot 20}$ $\mathrm{kPa}$ ), five had pressures between $40-49 \mathrm{~mm}$ $\mathrm{Hg}(5.33-6.53 \mathrm{kPa})$, and in one patient the pressure was just less than $80 \mathrm{~mm} \mathrm{Hg}(10.7$ $\mathrm{kPa}$ ). At the start of the study, supplemental oxygen via nasal cannula was being administered to one of the two patients with normal pressures ( $<30 \mathrm{~mm} \mathrm{Hg}, 4.00 \mathrm{kPa}$ ), three with

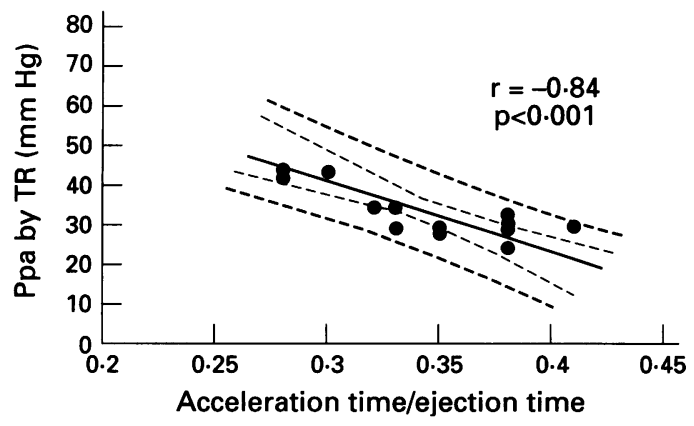

Figure $2 T R$ derived peak systolic pulmonary artery pressure (Ppa) plotted against AT:ET after an oxygen challenge.

pressures between $30-39 \mathrm{~mm} \mathrm{Hg}(4 \cdot 00-5 \cdot 20$ $\mathrm{kPa}$ ), and two with pulmonary artery pressures above $40 \mathrm{~mm} \mathrm{Hg}(5.33 \mathrm{kPa})$.

Pulmonary flow velocity ratios, AT:ET, AT:ETc and ATc, heart rate and oxygen saturations were plotted against the peak pulmonary artery systolic pressure from the TR jet. By linear regression analysis, AT:ET before and after oxygen challenge correlated better than other Doppler flow intervals with TR derived Ppa values. There was an inverse relation between AT:ET and calculated peak systolic Ppa before and during the oxygen challenge ( $\mathrm{r}=-0.72$ and -0.84 , respectively) (figs 1 and 2). The correlation was lower with the other variables.

Pulmonary Doppler flow velocities were obtained in all 12 control subjects. Two of these patients had measurable tricuspid regurgitation with normal calculated pulmonary systolic pressures. A significant difference between healthy infants and patients was found with all variables which was most striking for the 11 infants ( 15 examinations) with pulmonary artery pressures equal or greater than $35 \mathrm{~mm} \mathrm{Hg}(4.67 \mathrm{kPa})$ (table 1).

Eleven of the patients given an oxygen challenge had measurable tricuspid regurgitation (table 2). In three examinations low flow oxygen was being administered at the start. Despite this, however, saturations were below $95 \%$ in two (cases 2 and 8 ), probably as a result of the sedation. Reactivity to oxygen was found in eight patients with TR (12 examinations) in association with a concomitant rise in oxygen saturation. Simultaneously, a substantial increase in AT:ET was measured in all these patients (figs 3 and 4). No significant change in AT:ETc or ATc was found after administration of oxygen. Three patients were unreactive to oxygen despite an adequate rise in saturation. Case 11 (table 2) had very severe pulmonary hypertension and was exquisitely

Table 1 Mean (SD) pulmonary flow intervals in infants with CLD and in control infants

\begin{tabular}{|c|c|c|c|c|}
\hline & $A T: E T$ & $A T: E T c$ & $A T c$ & Heart rate per minute \\
\hline $\begin{array}{l}\text { All infants with CLD }(n=45) \\
\text { CI } \\
\text { CLD with Ppa of } \geqslant 35 \mathrm{~mm} \mathrm{Hg}(n=15) \\
\text { CI } \\
\text { Control infants }(n=12)\end{array}$ & $\begin{array}{l}0.334(0.049)^{\star \star} \\
-0.8,-0.02 \\
0 \cdot 296(0.029)^{\star \star} \\
-0 \cdot 11,-0.06 \\
0.385(0.039)\end{array}$ & $\begin{array}{l}0.485(0.08)^{\star \star} \\
-0.18,-0.09 \\
0.416(0.045)^{\star \star} \\
-0.25,-0.16 \\
0.624(0.06)\end{array}$ & $\begin{array}{l}118 \cdot 9(18 \cdot 2)^{\star} \\
-24 \cdot 2,-3 \cdot 3 \\
108 \cdot 4(12 \cdot 3)^{\star \star} \\
-35 \cdot 2,-13 \cdot 1 \\
132 \cdot 6(14 \cdot 6)\end{array}$ & $\begin{array}{l}126 \cdot 6(21)^{\star \star} \\
-38,-21 \cdot 6 \\
118 \cdot 4(19 \cdot 3)^{\star \star} \\
-49 \cdot 8,-26 \cdot 3 \\
156 \cdot 5(9 \cdot 3)\end{array}$ \\
\hline
\end{tabular}

AT:ET = acceleration time divided by ejection time; AT:ETc=AT:ET divided by the square root of the R-R interval on the electrocardiogram. ATc = acceleration time divided by the square root R-R interval on the simultaneous electrocardiogram: $\mathrm{Ppa}=$ pulmonary artery pressure in infants with tricuspid regurgitant jet; $n=$ number of observations; $\mathrm{CI}=95 \%$ confidence interval of difference between mean CLD and control values. Difference from control group: ${ }^{\star} \mathrm{p}<0 \cdot 05,{ }^{\star} \mathrm{p}<0 \cdot 01$. 
Table 2 Mean values of oxygen challenge (and during administration of oxygen) in those infants with pulmonary hypertension and TR

\begin{tabular}{|c|c|c|c|c|c|c|c|c|}
\hline $\begin{array}{l}\text { Case } \\
\text { No } \\
\end{array}$ & $\begin{array}{l}\text { Age } \\
\text { (months) }\end{array}$ & $\mathrm{O}_{2}$ & $\begin{array}{l}\text { Saturation } \\
(\%)\end{array}$ & $\begin{array}{l}\text { Ppa } \\
(\mathrm{mm} \mathrm{Hg})\end{array}$ & $A T: E T$ & $A T: E T c$ & $A T c$ & $\begin{array}{l}\text { Heart rate } \\
\text { per minute }\end{array}$ \\
\hline 1 & 12 & - & $85(96)$ & $35(30)$ & $0.31(0.35)$ & $0.41(0.49)$ & $113(120)$ & $110(100)$ \\
\hline & 13 & - & $91(95)$ & $35(27)$ & $0.34(0.36)$ & $0.48(0.51)$ & $126(130)$ & $119(115)$ \\
\hline 2 & $5 \cdot 5$ & + & $93(96)$ & $44(44)$ & $0.28(0.28)$ & $0.44(0.44)$ & $99(100)$ & $147(146)$ \\
\hline 3 & 9 & - & $95(96)$ & $44(44)$ & $0.29(0.30)$ & $0.40(0.41)$ & $112(114)$ & $110(108)$ \\
\hline & 14 & + & $96(97)$ & $42(42)$ & $0.33(0.34)$ & $0.47(0.48)$ & $120(119)$ & $120(128)$ \\
\hline 4 & 21 & - & $86(95)$ & $43(30)$ & $0.31(0.41)$ & $0.42(0.51)$ & $107(124)$ & $89(83)$ \\
\hline 5 & 23 & - & 87 (95) & $48(35)$ & $0.32(0.33)$ & $0.46(0.48)$ & 119 (124) & $125(115)$ \\
\hline & 25 & - & $92(95)$ & $44(35)$ & $0.29(0.33)$ & $0.39(0.46)$ & $114(120)$ & $112(108)$ \\
\hline 6 & 17 & - & $88(95)$ & $45(42)$ & $0.27(0.28)$ & $0.39(0.40)$ & $111(111)$ & $127(115)$ \\
\hline 7 & 21 & - & $96(97)$ & 41 (33) & $0.29(0.38)$ & $0.37(0.53)$ & $112(129)$ & $95(90)$ \\
\hline & 25 & - & $94(97)$ & $42(32)$ & $0.31(0.39)$ & $0.39(0.54)$ & $113(126)$ & $97(95)$ \\
\hline 8 & 12 & + & $90(96)$ & $38(30)$ & $0.28(0.35)$ & $0.38(0.55)$ & $92(120)$ & $114(100)$ \\
\hline 9 & 29 & - & $90(97)$ & $38(25)$ & $0.28(0.38)$ & $0.39(0.55)$ & $102(118)$ & $115(109)$ \\
\hline 10 & 3 & - & $94(97)$ & $42(35)$ & $0.28(0.32)$ & $0.44(0.47)$ & $102(108)$ & $157(145)$ \\
\hline 11 & $5 \cdot 5$ & - & $86(97)$ & $78(30)$ & $0.23(0.33)$ & $0.34(0.53)$ & $83(126)$ & $132(115)$ \\
\hline
\end{tabular}

$\mathrm{O}_{2}=$ maintenance oxygen treatment before study; *arterial saturations by oximeter; $\mathrm{Ppa}=$ pulmonary artery pressure calculated from TR.

sensitive to oxygen, with a dramatic drop in Ppa to normal values. Towards the end of the study, when sedation wore off, he awoke abruptly and dislodged the oxygen nasal cannula. The $\mathrm{SaO}_{2}$ dropped below $90 \%$, and a TR calculated pressure of above $60 \mathrm{~mm} \mathrm{Hg}$ $(8.00 \mathrm{kPa})$ was again recorded.

\section{Discussion}

Survival of very low birthweight infants has improved with advances in neonatal intensive care, but with a concomitant increase in the incidence of CLD. ${ }^{25-27}$ Pulmonary hypertension with its sequelae may be an important complicating factor in infants discharged home on supplemental oxygen. Pulmonary hypertension and cor pulmonale have been clearly demonstrated in infants with CLD by direct measurement, ${ }^{245}$ and by histological studies. ${ }^{27-29}$ The mechanisms responsible for the development and resolution of pulmonary hypertension in patients with CLD are unknown. Controversy exists as to whether the increased pulmonary vascular resistance is 'fixed' or can decrease in response to increasing concentrations of oxygen ('reactive'). ${ }^{2} 6$ One of the main aims of longterm domiciliary oxygen treatment $^{7}$ is to reduce pulmonary hypertension, but the amount of oxygen needed for optimal treatment is not clearly defined and may vary widely between patients. ${ }^{6}$

In this study we found Doppler evidence of TR in $44 \%$ of infants with CLD in the absence of clinical signs of TR. In most instances, the detection of TR was time consuming, taking up to 45 minutes. Colour flow mapping was very useful in directing the continuous wave Doppler beam. In many patients the best TR envelopes were obtained during inspiration. We suggest that this is due to the increased venous return to the right side of the heart which normally occurs during inspiration. In this small study the presence of a tricuspid regurgitant jet was unrelated to gestational age, duration of disease, or calculated right ventricular systolic pressure. Measurement of this echoDoppler velocity is the method of choice in the non-invasive assessment of pulmonary systolic pressure ${ }^{1022}$ and has been validated during cardiac catheterisation in infants. ${ }^{22}$ The major disadvantages of this method are the occurrence of TR in less than half of patients, the need for sedation, and the time taken to detect it.

Pulmonary systolic time intervals, on the other hand, are easier to obtain and were measurable in all patients. They are influenced by numerous variables, such as heart rate, ventricular function, and the Doppler sampling site within the pulmonary artery. ${ }^{16}$ Great care was taken to use a constant site in the centre of the pulmonary artery distal to the valve. Using two-dimensional imaging and $M$ mode echocardiography, right ventricular function was normal in all patients.

Pulmonary artery pressure from TR correlated inversely with the Doppler derived pulmonary time intervals AT:ET, AT:ETc, and ATc. Of the three pulmonary Doppler time ratios, AT:ET gave the best correlation; AT:ETc and ATc correlated poorly. We have concerns with regard to the accuracy of these dimensionless time ratios and intervals. Their major disadvantage is their approximate correlation with Ppa (systolic, mean, or diastolic). ${ }^{30}$ Figures 1 and 2 show that the wide 95\% confidence intervals make the prediction of Ppa inaccurate. Nevertheless, we found that the change in AT:ET accurately reflected the change in Ppa brought about by oxygen challenge (fig 3). As an empirical guide to pulmonary vascular reactivity, it could therefore be valuable.

Reactivity to oxygen was found in eight of 11 patients with $T R$, with a drop in tricuspid valve•

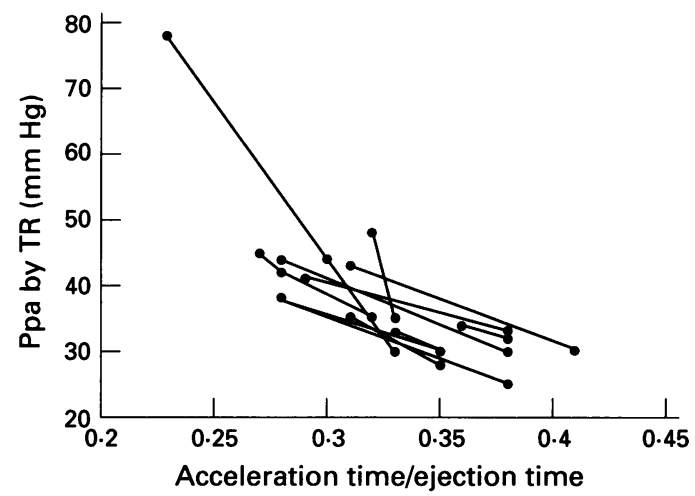

Figure 3 Values of TR and AT:ET before and after oxygen challenge in individual patients. Solid lines join values before and after an oxygen challenge. 


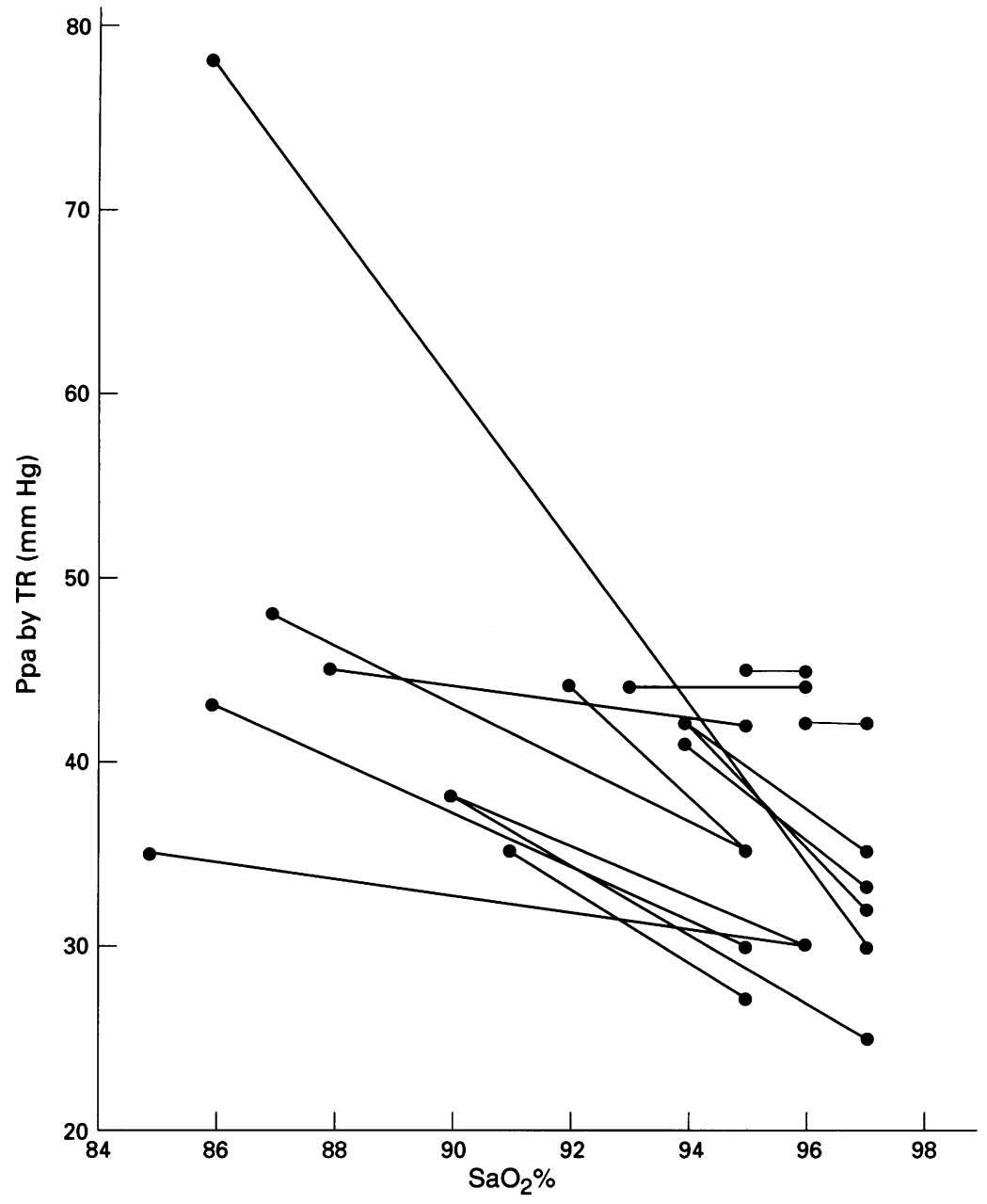

Figure 4 Effect of oxygen on TR derived peak systolic pulmonary artery pressure and measured oxygen saturation, $\mathrm{SaO}_{2}$. Solid lines join values before and after an oxygen challenge. the pulmonary arterioles or a reduction in the number of channels. Beyond 4 weeks of age, infants with CLD and pulmonary hypertension have substantial muscularisation of the pulmonary arterioles which progressively increases the longer the CLD is present. ${ }^{27} 29$ Goodman et al found that in infants with CLD complicated by pulmonary hypertension, maximum dilatation of the pulmonary vascular bed with oxygen was achieved when arterial oxygen saturations rose to or exceed $95 \%$. They also found that persistence of the pulmonary hypertension when supplemental oxygen was used carried a poor prognosis.

It is important to provide optimal oxygen treatment. Too little may be associated with the complications of chronic hypoxaemia; too much will lead to unnecessarily prolonged treatment and may be a factor in systemic hypertension. ${ }^{31}$ It is apparent from this study that normoxia (saturations equal to or above 95\%) may not necessarily abolish pre-existing pulmonary hypertension. Moreover, some patients with CLD were insensitive to oxygen treatment. Whether continuous administration of additive oxygen could afford protection to babies with pulmonary hypertension who are normoxic in ambient air was not determined in the present study.

Other factors, which may have an influence on the 'vascular tone' of the pulmonary vascular bed, such as $\mathrm{pH}, \mathrm{PCO}_{2}$, sedatives, and intercurrent 'viral' infections, need to be taken into account when assessing pulmonary hypertension. All infants with CLD ought to be regularly evaluated for pulmonary artery pressure and if indicated given an oxygen challenge to determine 'reactivity', as the symptoms and signs of pulmonary hypertension cannot be relied on and are apt to be obscured by the underlying respiratory disease.

Oxygen, a very potent pulmonary vasodilator, remains the mainstay of treatment for infants with CLD to prevent pulmonary hypertension and its consequences. The variability in $\mathrm{Ppa}$ in relation to oxygen saturation, seen in patients with CLD, necessitates individual adjustment, and echoDoppler evaluation of Ppa, particularly in the presence of $T R$, is an important non-invasive tool in its assessment. The role of echocardiography in the management of oxygen treatment in CLD should now be subject to evaluation by appropriate clinical trials.

We thank Action Research for financial support and the Adrian Bouwer Trust for the equipment grant which made the research possible.

1 Bancalari E, Gerhardt T. Bronchopulmonary dysplasia Pediatr Clin North Am 1986; 33: 1-23.

2 Berman W Jr, Yabek SM, Dillon T, Burstein R, Corlew S. Evaluation of infants with bronchopulmonary dysplasia
using cardiac catheterization. Pediatrics 1982; 70: 708-12. 3 White MP, Houston AB. Pulmonary hypertension in bronchopulmonary dysplasia. Arch Dis Child 1990; 65: bronch.

4 Bush A, Busst CM, Knight WB, Hislop AA. Haworth SG, Shinebourne EA. Changes in pulmonary circulation in severe bronchopulmonary dysplasia. Arch Dis Child 1990; 65: 739-45

5 Goodman G, Perkin RM, Anas NG, Sperling PR, Hicks $D A$, Rowen $M$. Pulmonary hypertension in infants with bronchopulmonary dysplasia. $\mathcal{F}$ Pediatr 1988; 112: 67-72. 6 Abman SH, Wolfe RR, Accurso FJ, Koops BL, Bowman CM, Wiggins JW. Pulmonary vascular response to oxygen in infants with severe bronchopulmonary dysplasia. Pediatrics 1985; 75: 80-4. 
7 Pinney MA, Cotton EK. Home management of bronchopulmonary dysplasia. Pediatrics 1976; 58: 856-9.

8 Skinner JR, Boys JR, Hunter S, Hey EN. Non-invasive assessment of pulmonary arterial pressure in healthy neonates. Arch Dis Child 1990; 66: 386-90.

9 Skinner JR, Boys JR, Hunter S, Hey EN. Pulmonary and systemic arterial pressure in hyaline membrane disease. Arch Dis Child 1992; 67: 366-73.

10 Chan KL, Currie PJ, Seward JB, Hagler PJ, Mair DD, Tajik AJ. Comparison of three Doppler ultrasound methods in the prediction of pulmonary artery pressure. $\mathcal{F} \mathrm{Am}$ Coll the prediction of pulmo
Cardiol 1987; 9: 549-54.

11 Berger M, Haimowitz A, Van Tosh A, Berdoff RL, Goldberg E. Quantitative assessment of pulmonary hypertension in patients with tricuspid regurgitation using continuous

wave Doppler ultrasound. f Am Coll Cardiol 1985; 6: 359-65

12 Yock PG, Popp RL. Noninvasive estimation of right ventricular systolic pressure by Doppler ultrasound in patients with tricuspid regurgitation. Circulation 1984; 70: 657-62.

13 Kitabatake A, Inove M, Asao M, Masuyama T, Tanouchi J, Morita $\mathrm{T}$, et al. Noninvasive evaluation of pulmonary hypertension by a pulsed Doppler technique. Circulation 1983; 68: 302-9.

14 Kosturakis D, Goldberg SJ, Allen HD, Loeber C. Doppler echocardiographic prediction of hypertension in congeniechocardiographic prediction of hypertension in con

15 Matsuda M, Sekiguchi T, Sugishita Y, Kuwako K, Iida K, Ito I. Reliability of non-invasive estimates of pulmonar hypertension by pulsed Doppler echocardiography. $\mathrm{Br}$ Heart $\mathcal{1}$ 1986; 56: 158-64.

16 Serwer GA, Cuogle AG, Eckard JM, Armstrong BE. Factors affecting use of the Doppler-determined time from flow onset to maximal pulmonary artery velocity for measurement of pulmonary artery pressure in children. Am 7 Cardiol 1986; 58: 352-6.

17 Akibe T, Yoshikawa M, Otaki S, Kobayashi Y, Nakasato M, Suzuki H, et al. Prediction of peak pulmonary artery pressure by continuous-wave Doppler echocardiography pressure by continuous-wave Doppler echocardiograp

18 Martin-Duran $R$, Larman $M$, Trugeda $A$, Vazquez De Prada JA, Ruano J, Torres A, et al. Comparison of Doppler-determined elevated pulmonary arterial pressure with pressure measured at cardiac catheterization. $A m \mathcal{F}$ Cardiol 1986; 57: 859-63.

19 Hatle L, Angelsen B, eds. Physics of blood flow. In: Doppler ultrasound in cardiology. Philadelphia: Lea and Febiger, 1985: 22-6.

20 Skjaerpe T, Hatle L. Noninvasive estimation of systolic pressure in the right ventricle in patients with tricuspid regurgitation. Eur Heart f 1986; 7: 704-10.

21 Burnard ED, James LS. Atrial pressures and cardiac size in the newborn infant. $\mathcal{F}$ Pediatr 1963; 62: 815-26.

22 Skinner RJ, Stuart GA, O'Sullivan J, Heads A, Boys RJ, Hunter S. Right heart pressure determination by Doppler in infants with tricuspid regurgitation. Arch Dis Child 1993; 68: 216-20.

23 Evans NJ, Archer LNJ. Postnatal circulatory adaptation in healthy term and preterm infants. Arch Dis Child 1990; 65: 24-6.

24 Evans NJ, Archer LNJ. Doppler assessment of pulmonary artery pressure and extrapulmonary shunting in the acute phase of hyaline membrane disease. Arch Dis Child 1991; 66: 24-6.

25 Northway WH, Rosan RC, Porter DY. Pulmonary disease following respiratory therapy of hyaline membrane disease: Bronchopulmonary dysplasia. $N$ Engl $f$ Med 1967; 276: 357-68.

26 Northway $H$ Jr. Bronchopulmonary dysplasia: then and now. Arch Dis Child 1990; 65: 1076-81.

27 Taghizadeh A, Reynolds EOR. Pathogenesis of bronchopulmonary dysplasia following hyaline membrane disease. Am $\mathcal{F}$ Pathol 1976; 82: 241-64.

28 Bonikos DS, Bensch KG, Northway WH. Bronchopulmonary dysplasia: The pulmonary pathologic sequel of necrotising bronchiolitis and pulmonary fibrosis. Hum Pathol 1976; 7: 643-66.

29 Tomashefski JF Jr, Opperman HC, Vauter GF, Reid LR. Bronchopulmonary dysplasia: a morphometric study with emphasis on pulmonary vasculature. Pediatr Pathol 1984; 2: 469-87.

30 Gill AB, Weindling AM. Pulmonary artery pressure changes in the very low birthweight infant developing chronic lung in the very low birthweight infant developing chronic lung

31 Abman SH, Warady BA, Lum GM, Loops BL. Systemic hypertension in infants with bronchopulmonary dysplasia. f Pediatr 1984; 104: 928-31. 